\title{
Visual Crisis Communication in the Scandinavian Press
}

\author{
Images of the MS Estonia disaster
}

\author{
Carmen Daniela Maier ${ }^{I}$, Finn Frandsen ${ }^{\text {II }}$ \& Winni Johansen ${ }^{\text {III }}$ \\ I Department of Communication and Culture, Aarhus University, Denmark \\ II, III Department of Management, Aarhus University, Denmark
}

\begin{abstract}
This study marks a shift in research focus from verbal to visual aspects in crisis communication and contributes to the emerging field of visual crisis communication by exploring the use of images in the Scandinavian press when reporting on and/or commemorating a disaster. We used rhetorical arena theory (RAT) and a social semiotic approach to visual analysis to investigate how fifteen newspapers from Sweden, Norway and Denmark visualised the MS Estonia disaster ten, fifteen and twenty years after the sinking of the ship. We examined 93 images published on the anniversaries in 2004, 2009 and 2014 to determine what kinds of images accompanied the press reports and how these changed over time. The results demonstrate that the images, which changed considerably over time, represented the disaster both as an irreversible loss and as a process with a strong symbolic value.
\end{abstract}

Keywords: crisis communication, rhetorical arena theory, Scandinavian press, social semiotics, visual communication

\section{Introduction}

The news media play a key role before, during and after a disaster: 'Reporters become the investigators, critics, and historians of the disaster' (Horsley, 2016: 155). In this article, we study how the press in three Scandinavian countries visually covered one of the worst maritime disasters of the twentieth century through the images that accompanied news reports. On 28 September 1994, the cruise ferry MS Estonia sank in the Baltic Sea on its way from Tallinn to Stockholm. Within less than an hour, 852 out of 989 people (crew and passengers) lost their lives, including 501 Swedes, 6 Norwegians and 5 Danes. The majority of the bodies were never recovered. At the time of the disaster, the MS Estonia was owned by Estline Marine Company Limited. The joint Estonian/Finnish/ Swedish Accident Investigation Commission (JAIC) set up on 29 September 1994 did not end its investigation until December 1997, concluding in its final report that failure of the bow door caused the accident. In the aftermath of the disaster, the victims' relatives

Maier, C. D., Frandsen, F. \& Johansen, W. (2019). Visual crisis communication in the Scandinavian press: Images of the MS Estonia disaster in Nordicom Review, 40(2): 91-109. doi:10.2478/ nor-2019-0035. 
established close relatives groups and civil associations. They demanded that their loved ones be raised from international waters for land burial in their home countries (Bos et al., 2005). This triggered a second crisis, this time between the Swedish government and the civil associations. Invoking the practical difficulties and the moral implications, the Swedish government suggested burying the ship in situ with a shell of concrete. Obviously, the disaster was visually present in the newspapers not only immediately after it happened but also throughout the following two decades, especially at the time of three key anniversaries (2004, 2009 and 2014).

Few crisis communication researchers have examined the visual dimension of crisis communication. Most cases have focused on how various types of visual elements affect stakeholder perceptions and reactions. Fahmy and colleagues (2006) and Miller and LaPoe (2016) investigated the impact of disaster imagery from an agenda-setting perspective, while Dahmen and Miller (2012) approached the same topic from an iconicity perspective. Based on the framework of situational crisis communication theory and an experimental research design, Coombs and Holladay (2011) examined the impact of victim visuals in two product harm crisis scenarios on perception of crisis responsibility; their results revealed only a minimal effect, suggesting that news images do not intensify the threats posed by crises. Using a similar approach, Claeys and Cauberghe (2014) investigated the impact of visual expressions of power by organisational spokespersons during different stages of a crisis, finding that powerful behaviour during a crisis minimised reputational damage by increasing the perceived competence, while powerless behaviour affected the organisational reputation positively through an increase in perceived sincerity. Recently, Liu and colleagues (2017) found that visuals - in this case maps in short governmental warning messages - improved the public's comprehension of crisis and disaster information. Although visual communication has seemed to gain traction within public relations (e.g. Collister \& Roberts-Bowman, 2018, and the special section in Public Relations Review 2018: 44[3]), only a few studies connected visuals and crisis communication (for a detailed overview, see Maier, 2020).

The literature on media and disasters has some relevance to the study of visual crisis communication. One study of the seven functions of disaster rhetoric and the media memorialisation of disasters in the crisis aftermath found that 'with news footage or photography files available "the media loves an anniversary of a disaster" (Courtright \& Slaughter, 2007: 316). The overview in Joye (2014) draws on the idea of a disaster as a social and media construction; that is, 'Disasters and crises today are principally defined, dramatized and constituted in and through media and communication' (WahlJorgensen \& Cottle, 2012: 33). Distant suffering, or the moral and political implications for a spectator of the distant suffering of others as presented through the media (Boltanski, 2004), may serve as an illustration.

The literature on the MS Estonia disaster is more comprehensive than the visual crisis communication literature as such, but has encompassed a wide range of research topics (i.e. (post)traumatic stress, survivors) and academic disciplines (psychology, sociology, crisis management). The study by Bos and colleagues (2005) considered the MS Estonia disaster and investigated what they called the politics of disaster (inspired by the politics of crisis management, Boin et al., 2005) to answer the question: Why do some crises transform into social icons, whereas others just remain crises? They claimed that the extent and nature of disaster remembrance is not just a question of the number of casualties or degree 
of social disturbance caused at the time, but rather should be viewed as the product of 'a political encounter between grass-roots memory and the elite-level, political "processing" of disasters' (Bos et al., 2005: 5-6). Rather than determining disaster politics, the present study explores in detail the images visualising this crisis across decades.

The present longitudinal study has been based on a comprehensive social semiotic analysis of the MS Estonia disaster press images over two decades. We have not focused on the images of the disaster event (1994) as such, but rather investigated the images used by the Scandinavian press when discussing the event 10, 15 and 20 years later, either to cover new developments or to commemorate it. The present investigation of visual communication has been done without considering the newspaper articles in their entirety. Following Bednarek and Caple's analysis of news images, in this study 'we restrict our analysis to examining the image only' (2017: 107). References to captions have only occasionally been made, as we also assume that news images can be used 'to attract readers to a particular story, encourage readers to engage more deeply with an issue or they can even be the story themselves' (Bednarek \& Caple, 2017: 107). We are interested in what newspaper readers can understand before they start reading an article, because we consider that the first visual impression 'colours' the subsequent reading. Because the present study focuses on the fine-grained analysis of visuals, an investigation of the text-image relationship is also beyond its scope; we are primarily interested in 'the visual aspect of journalism', specifically in how news images are used in 'documenting and symbolising events' (Machin \& Polzer, 2015: 21). Similarly, journalists' ethical guidelines are not focused or discussed because we do not seek to explore how journalists' values are mirrored in the selection of the disaster images. These aspects may be considered at a later date as part of a larger research project.

\section{Theoretical framework}

The theoretical framework is informed by rhetorical arena theory (RAT) and the multivocal approach to crisis communication (Frandsen \& Johansen, 2010, 2017a). The overall aim of RAT is to study the communicative complexity of crises. This complexity is reflected in the definition of crisis communication as:

a complex and dynamic configuration of communicative processes which develop before, during, and after an event or a situation that is interpreted as a crisis by an organization and/or by other voices in the arena. Crisis communication also includes how various actors, contexts, and discourses (manifested in specific genres and specific texts) relate to each other. (Frandsen \& Johansen, 2017a: 148)

These manifestations include visual genres and texts, such as press photos, amateur photos, citizen imagery, films and even safety instructions graphics. For a genre typology of journalistic photographs, see for instance Kedra (2016). The theory also applies a semiotic perspective: 'not only the spoken and written word, but also visuals, actions, and artifacts, may serve as resources when people communicate' (Frandsen \& Johansen, 2017a: 149). RAT takes as its starting point a very simple observation that anyone can make when a crisis occurs - that many actors or voices start communicating in various ways, not only the organisation in crisis, but also customers, employees, politicians, activist groups and the media. This creates a much broader idea of what crisis communication is. 
RAT is a theory of the social space that opens up when a crisis breaks out, a space located across traditional distinctions between public and private spheres, and between stakeholders and non-stakeholders. Inside this new social space, multiple voices communicate about, to, with, past or against each other, creating specific patterns of interaction. A persuasive attack followed by a verbal defense can be considered the smallest interaction pattern, while a blame game is a more dynamic and complex version. A multi-crisis involving many organisations and intermediaries creates even more dynamic and complex patterns (Frandsen \& Johansen 2017a).

In our present study of the MS Estonia disaster, we focus exclusively on the voices of the news media - here, newspapers from Sweden, Norway and Denmark. In crisis communication research, the news media are often seen as a strong and powerful external stakeholder that produces representations of an 'outside world'. What began as Lippmann's (1922) 'pictures in our heads' has today transformed into an omnipresent process of mediatisation - that is, 'the extension of the influence of the media (considered both as a cultural technology and as an organization) into all spheres of society and social life' (Lundby, 2009: 5; cf. Patrona, 2018). This approach, however, runs the risk of becoming too media-centric, ignoring the entangled interactions between the news media and organisations (Pallas \& Fredriksson, 2013).

Boin et al. describe the news media as 'a pivotal force in discovering, conveying, and (de)escalating crises' (2005: 72). The news media also function as meaning makers: through their framing of the crisis event they influence peoples' perceptions and attributions of crisis responsibility. It is therefore no surprise that the news media are sometimes viewed as a defining element of a crisis and are a convenient source from which to collect data about other voices in the arena. The concept of media coverage (i.e. crisis representation) and the idea of the news media as a stakeholder by proxy are closely related to this understanding of the news media. Both theoretically and methodologically speaking, however, this approach is problematic because it reduces the news media to a simple channel and makes us forget that the data we collect from the news media have been recontextualised in various ways. Instead, we advocate in favour of the concept of media intervention (a 'contribution' to the crisis) and the idea of the news media as a genuine stakeholder or intermediary (Frandsen \& Johansen, 2015). Space limitations do not allow us to elaborate on this approach, but it provides a more sophisticated platform for studying the voices of the news media in the rhetorical arena.

The last element of our theoretical framework is remembrance history, which is based on the following definitions: (1) the past is defined as everything that happened at a specific point in time; (2) memory is the individual and collective representation of parts of the past; and, finally, (3) history is the interpretation of remembered parts of the past. A social icon can thus be defined as a past event which has become part of history in the present in specific ways.

\section{Research questions}

This study seeks to contribute to the emerging field of visual crisis communication by exploring the use of images in Scandinavian press when reporting on and/or commemorating the MS Estonia disaster after the event and addressing the following research questions: 
RQ1: What kinds of images accompanied the Scandinavian press reports about the MS Estonia disaster in 2004, 2009 and 2014?

RQ2: How did the images change over time?

\section{Research design}

This study is part of a larger research project investigating how the news media reflect on and contribute to the social construction of crises as 'social icons, around which broader meaning is constructed, maintained, symbolized and conveyed' (Seeger et al., 2003: 6). These social icons can be used to address research questions such as: How and to what extent does the Scandinavian press cover and intervene in the commemoration of crises and how do they contribute to the iconic status of specific crises, such as the MS Estonia (Frandsen \& Johansen, 2017b)?

To gain insight into visual crisis communication, we conducted a longitudinal case study (Bryman, 2012) of a single but complex disaster, focusing on how the visual representations of the disaster had changed over time. The study was based on all of the images published by 15 important Swedish, Norwegian and Danish newspapers over a period of two decades at five-year intervals corresponding to key anniversaries of the MS Estonia disaster (for a data overview, see Table 1).

Table 1. Number of images per newspaper and year

\begin{tabular}{lccc}
\hline \multicolumn{2}{l}{$\mathbf{2 0 0 4}$} & $\mathbf{2 0 0 9}$ & $\mathbf{2 0 1 4}$ \\
\hline Denmark & 0 & 0 & 0 \\
Berlingske & 0 & 0 & 3 \\
BT & 0 & 0 & 7 \\
Ekstra Bladet & 0 & 0 & 3 \\
Jylland-Posten & 0 & 0 & 1 \\
Politiken & & & \\
Norway & 0 & 0 & 3 \\
Adresseavisen & 0 & 0 & 3 \\
Aftenposten & 0 & 0 & 1 \\
Bergens Tidende & 0 & 0 & 2 \\
Stavanger Aftenblad & 2 & 0 & 3 \\
VG & & & \\
Sweden & 0 & 0 & 38 \\
Aftonbladet & 5 & 1 & 6 \\
Dagens Nyheter & 0 & 0 & 7 \\
Expressen & 0 & 0 & 1 \\
Göteborgs-Posten & 0 & 1 & 6 \\
Svenska Dagbladet & 7 & 2 & 84 \\
\hline Total & & & \\
\hline
\end{tabular}


The 93 images consisted of individual, full-page and composite (overlapping or separated by frames) photos, as well as individual and composite graphic images. Four distinct coding parameters were selected to classify and annotate each visual representation: context, image type, accompanying text and metafunctional features (see Table 2).

Table 2. Overview of the parameters used for image analysis

\begin{tabular}{|c|c|c|c|}
\hline Parameter categories & \multicolumn{3}{|c|}{ Parameter subcategories } \\
\hline \multirow[t]{3}{*}{ Contextual } & \multicolumn{3}{|c|}{ Publication date } \\
\hline & \multicolumn{3}{|l|}{ Newspaper } \\
\hline & \multicolumn{3}{|l|}{ Country } \\
\hline \multirow[t]{3}{*}{ Typological } & \multicolumn{3}{|l|}{ Photo } \\
\hline & \multicolumn{3}{|l|}{ Graphics } \\
\hline & \multicolumn{3}{|l|}{ Composite } \\
\hline \multirow[t]{3}{*}{ Accompanying text } & \multicolumn{3}{|l|}{ Title } \\
\hline & \multicolumn{3}{|l|}{ Caption } \\
\hline & \multicolumn{3}{|c|}{ Explanatory text } \\
\hline \multirow[t]{17}{*}{ Metafunctional } & \multirow[t]{5}{*}{ Ideational } & Narrative & Action \\
\hline & & & Reaction \\
\hline & & Conceptual & Symbolic \\
\hline & & & Analytic \\
\hline & & & Classifying \\
\hline & \multirow[t]{7}{*}{ Interpersonal } & Contact with viewer & Demand \\
\hline & & & Offer \\
\hline & & Distance & Personal \\
\hline & & & Impersonal \\
\hline & & & Social \\
\hline & & Point of view & Involvement \\
\hline & & & Detachment \\
\hline & \multirow[t]{5}{*}{ Textual } & Salience & \\
\hline & & Framing & Connection \\
\hline & & & Disconnection \\
\hline & & Information value & Centred \\
\hline & & & Polarised \\
\hline
\end{tabular}

The images were examined at the level of ideational, interpersonal and textual metafunctions, applying Kress and van Leeuwen's (2006) social semiotic conceptual framework to code the images. Using these analytical tools, the empirical investigation went beyond pure content analysis while preserving a tighter analytical focus. According to social semioticians (Kress \& Van Leeuwen, 2006), an image accomplishes these three metafunctions simultaneously. The strategies chosen to represent people, places and things yield the ideational metafunction, and we explored how narrative and conceptual visual structures mediated reality. While narrative structures are concerned with the representation of unfolding events, conceptual structures represent participants and 'their more generalized 
and more or less stable and timeless essence, in terms of class, or structure or meaning' (Kress \& Van Leeuwen, 2006: 79). Symbolic suggestive structures have a special relevance here because these 'are about what a participant means or is', and symbolic suggestive images depict 'not a specific moment but a generalized essence' (Kress \& Van Leeuwen, 2006: 112). The symbolic meaning and identity of the participants are presented as coming from within by de-emphasising the details of representation. The choice of one structure or a multidimensional structure can produce a different representation of the same aspects of reality as 'visual structures are never merely formal: they have a deeply important semantic dimension' (Kress \& van Leeuwen, 2006: 47). The interpersonal metafunction of images concerns the relationship between the visual representation and the viewer to convey a sense of interaction or its absence. The textual metafunction made it possible to explore images' compositional parameters.

Using a FileMaker Pro 12 Advanced database, we captured both the metafunctional and contextual parameters of the studied images. Each of the metafunctional parameters for each image were included in the database because, when verbalising the visual to this degree of accuracy, if the relevant image features are accurately transcribed then part of the analytical work is already generated. The database record for each of the 93 images also included contextual coordinates such as newspaper name, country of origin and date of publication, allowing the extraction of information about images' particular metafunctional choices and correlation to specific newspapers, countries and dates (Table 1). The integration provided by the relational database allowed the systematic exploration of the dynamic character of the changes in the visual representation of the disaster across time. Such techniques are 'particular useful for qualitative analysis', although 'the initial design, construction, and manual population of database fields are time-consuming' (Bednarek \& Caple, 2017: 15). Three researchers executed these tasks in parallel to ensure the accuracy, consistency and reliability of data coding according to the above-mentioned parameters. Three researchers independently coded a sub-sample of 20 images to improve coding reliability and accuracy, and the consistency of the interpretation; ambiguous cases were resolved by consensus.

\section{Results}

To provide answers to RQ1 and RQ2, 93 images from 2004, 2009 and 2014 were analysed vis-à-vis the three metafunctions each image performs: to provide visual representations of actors and actions, to position the viewers and to organise visual information in meaning-making layout structures. The changes occurring in the visualisation of the disaster from one commemorative milestone to another are then discussed. This article presents in detail findings related to only the first two metafunctions - ideational and interpersonal - due to space limitations.

\section{Visual representations of the MS Estonia disaster}

The selections made by the Scandinavian press for the ideational metafunction were probably motivated by the need to visualise both the impact of the disaster and the lack of real closure due to the unclear circumstances causing the tragic event. Both conceptual and narrative images were selected for publication. 
Conceptual images. In 1999, five years after the disaster, the symbolic suggestive image of a huge cross marks the irreversible loss (see Figure 1).

Figure 1. Page section of Dagens Nyheter, 27 September 1999

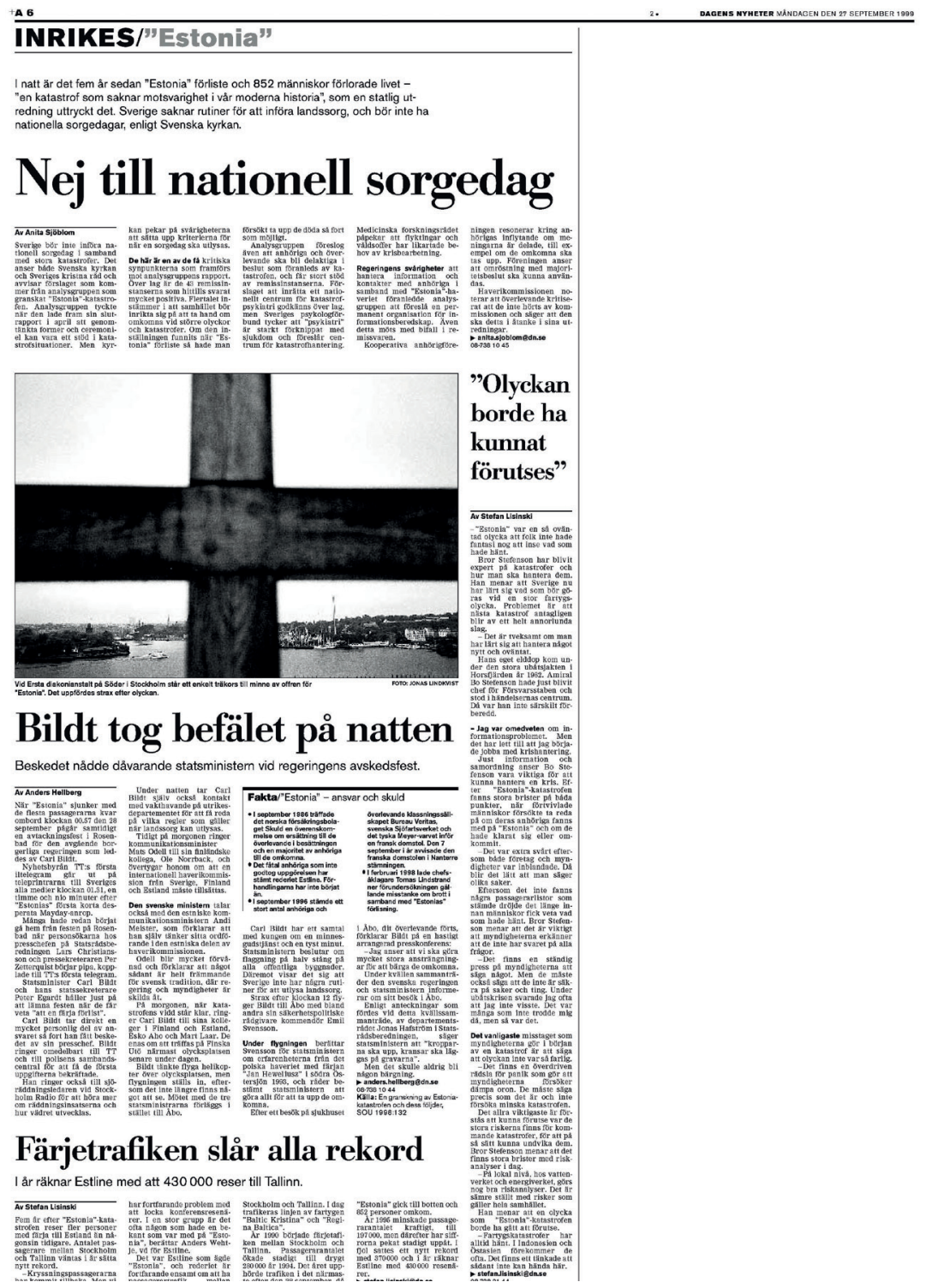

In 2004, ten years after the disaster, only three conceptual images appeared and all of them visualised the same irreversible loss, which was visualised either through an absence or representation of what was left of the MS Estonia. Two images symbolically visualised the void left after the disaster by representing long shots of a marine landscape. The dramatic light of a sunset highlights the absence of the cruise ferry on an image of the immense sea and sky (see Figures 2 and 3). 
Figure 2. Page section of Dagens Nyheter, 27 September 2004

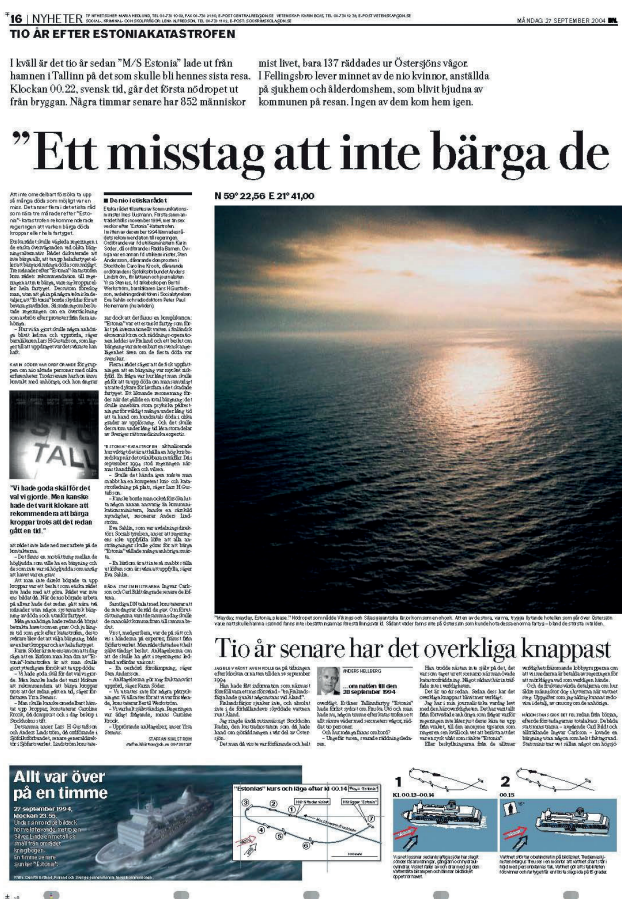

Figure 3. Page section of Dagens Nyheter, 28 September 2004

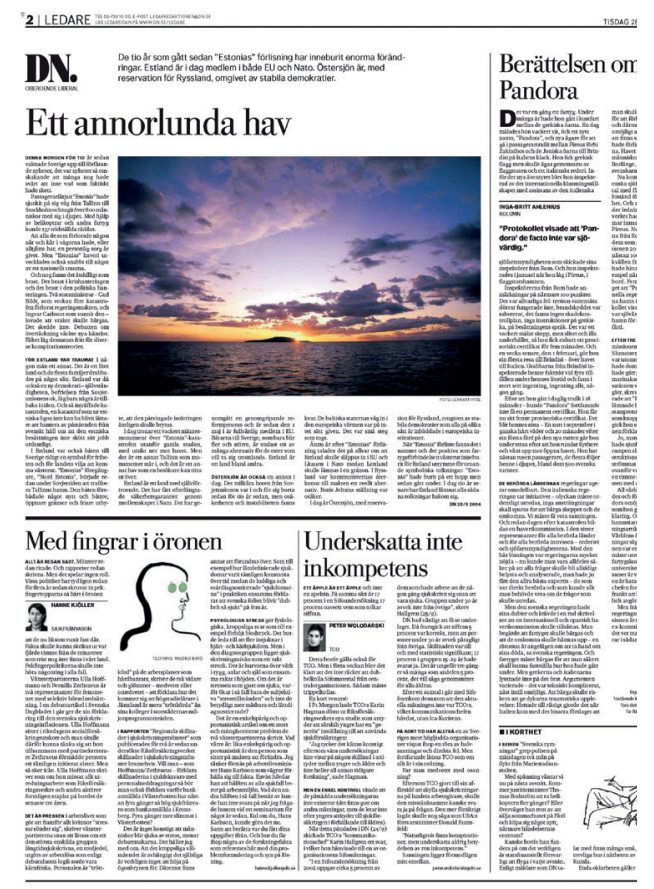


The third image analytically visualised the same loss in terms of concrete consequences: a photo taken by a remotely operated underground vehicle (ROV) shows the shipwreck, on part of which the ship's name can be seen (see Figure 2). In 2009, fifteen years after the disaster, the same close-up ROV photo was the only selected conceptual image.

In 2014, twenty years after the disaster, the ROV photo was published again, twice, the repetition endowing it with a symbolic value in the eyes of viewers (see Figure 4).

Figure 4. Page section of Aftonbladet, 28 September 2014

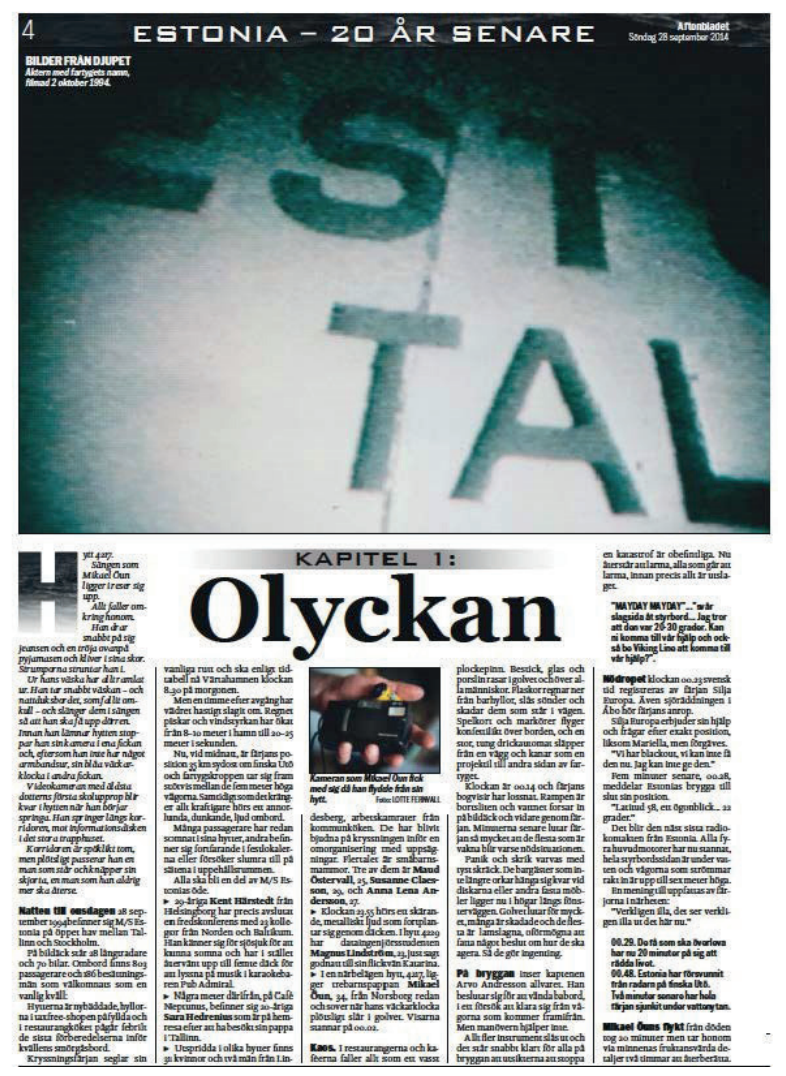

Apart from this photo, a wide range of conceptual representations was selected. The void left after the disaster was visualised symbolically: first by a long shot of the empty sea and then by two long shots of the MS Estonia before sinking. These also symbolised absence, because only the name of the Estline maritime company, the owner of the cruise ferry, was visible on the port side of the ship, not the name of the ship itself. Through a graphic visualisation of the MS Estonia, the absence appeared visually through the similarity between the graphic representation and the lost ship.

Three long shots, one of an empty life raft and two of the same capsized boat also symbolically represented this absence by replacing the majestic ship with small empty vessels. A similar strategy is used in a close up shot cabin keys held by a survivor. On the commemorative date of the disaster, the front page of a Swedish newspaper was symbolically covered by a graphic image of the ship's name - instead of the whole ship - floating on a black sea (see Figure 5). 
Figure 5. Front page of Aftonbladet, 28 September 2014

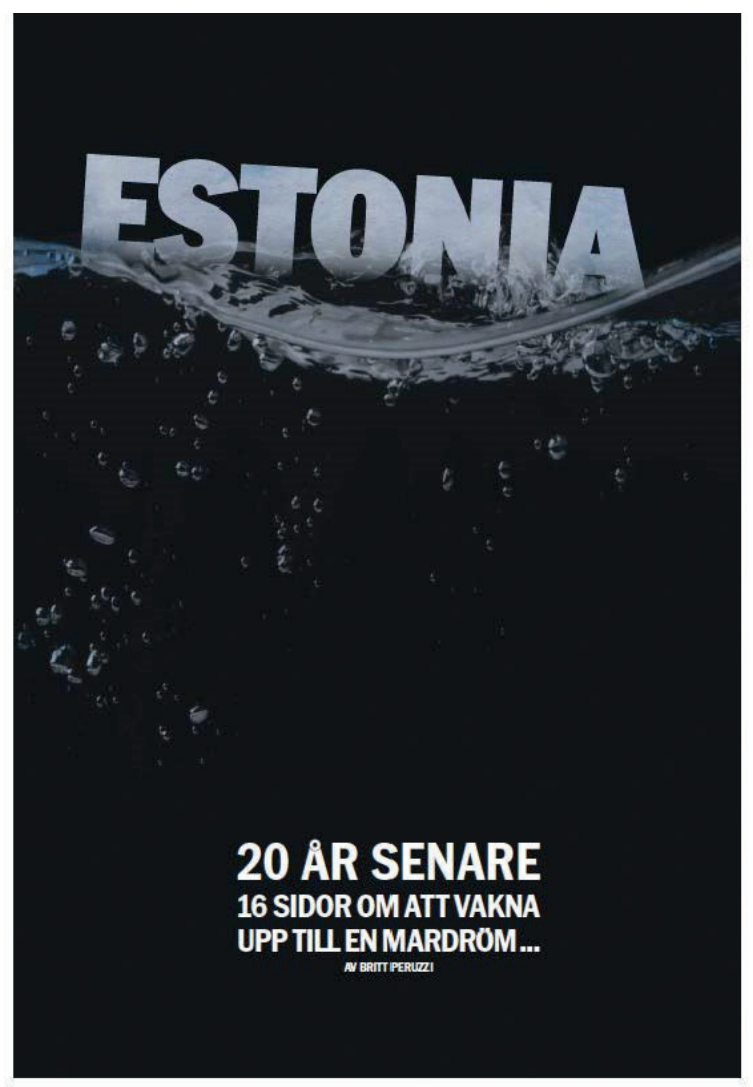

The choice to publish such visual replacements has a strong symbolic value because viewers are intended to imagine both the ship and the shipwreck when confronted by such images, and 'in this kind of image detail tends to be de-emphasized in favour of what could be called "mood" or "atmosphere" (Kress \& Van Leeuwen, 2006: 110), imbuing the image with symbolic meanings.

In 2014, the catastrophe was also represented as a process: two maps representing analytically the ship's final hour before sinking. The consequences of the disaster were also represented through classifying representations of two similar long shots of rows of coffins behind a uniformed man. Another classifying representation visualised the consequences through a long shot of a group of orphans in front of a monument dedicated to the tragic event. Other conceptual images were also implicitly linked to the consequences of the tragedy, through medium shots of a diver, rescuer and surgeon, for example. Those images visually highlighted the identity of the represented social actors. A greater diversity of shots was chosen to visualise victims and survivors, but these cannot be identified without reading the accompanying captions. If the selected conceptual images focused on visualising irreversible states of affairs or identities, the narrative images were characterised by dynamic representations through the presence of various types of vectors in each image. 
Narrative images. In 2004, one of the selected narrative images employed graphic visualisation in a triple-layered composite image of how the disaster had taken place (See Figure 2 from Dagens Nyheter, September 2004). In 2014, similar narrative images visualise the same tragic development (see Figure 6).

Figure 6. Page section of Aftonbladet, 28 September 2014

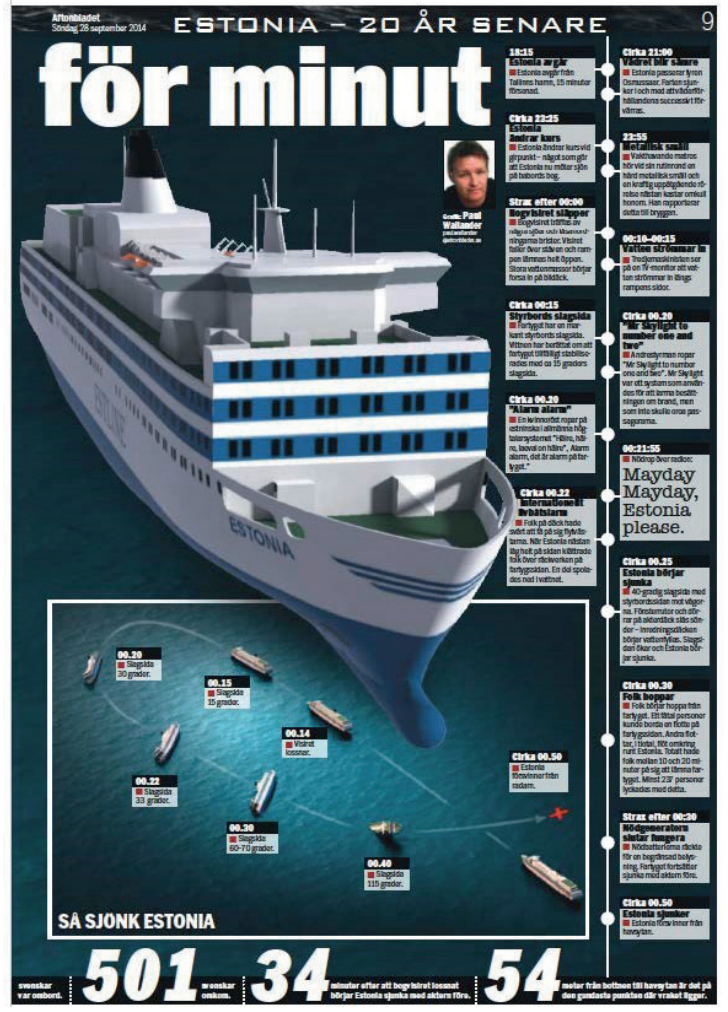

The other two narrative images from 2004 were photos of survivors dealing with the loss: in front of the MS Estonia memorial wall pointing at the names written on it and at home with a newspaper in front of them. In 2009, only one narrative image was published, a long shot of a group of people facing a big cross with flowers on the ground at Ersta Church in Sweden. The sea in the background both represented the loss and reminded viewers of its presence.

In 2014, the Scandinavian press chose to publish a particular narrative image no less than seven times: the dramatic hoisting operation of the wreck's bow door. The shot highlighted not only the wreck, but also the red crane hoisting it up in the light of a ship's head projectors. As that narrative image was the most used image across the three countries, it also acquired symbolic value through repetition. The selected visual representations of the rescue operations included images of survivors on a life raft, coming out of a helicopter and on a stretcher in front of ambulances. Images of an airborne helicopter and a life raft seen from the helicopter enhanced the narrative character of the images.

The dramatic character of the selected narrative representations was enhanced by 
images representing the grief and emotions of survivors hugging each other, talking to each other or surrounded by family members. One of the survivors holds his photo, taken by chance by another survivor, while signalling with the camera flash from a life raft. The photo shows him as the last person standing on Estonia's hull -the last person to be saved. The same photo was published again as a background for a medium shot of the two survivors 20 years later. Because so few survivor stories can be represented, the repetition is not surprising and perhaps enhances the viewers' emotional involvement.

Overall, the disaster was visually represented as a process: before it happened (through graphic images), while it happened (through graphic images) and after it happened (through photos of the shipwreck, social actors and their actions). Four main categories of actors were visually represented: (1) victims, (2) survivors, (3) family members and (4) outsiders (e.g. rescuers, a diver or even the King of Sweden). No representatives of the maritime company appeared. The only official person represented in all 93 images related to the disaster was the King of Sweden laying flowers on the memorial wall in Stockholm. The lack of other officials in the visual material selected to commemorate the disaster may be linked to the lack of clear explanations of the causes and satisfying motivations for salvaging the whole shipwreck. These actors were involved in two main types of actions related to the aftermath of the disaster: rescue operations and commemorative meetings. When not involved in these actions, the actors were represented as being explicitly in dialogue with each other or implicitly in dialogue with the viewers. The objects appearing in the images included the ship before the disaster, parts of the shipwreck, life rafts and boats, other ships, ambulances, helicopters and coffins.

\section{Visual positioning of viewers}

The images also created and maintained an interaction between the visual representation and viewers through demand or offer images. In 2004, only one demand image was published; a Norwegian newspaper represented a grieving couple in their kitchen with a newspaper in front of them. Apart from their direct gaze, the home environment brought them closer to the viewers and strengthened the expected emotional involvement. In 2009, no demand images were published in any of the newspapers. In 2014, however, several categories of actors gazed directly at the viewers: three victims, several survivors and rescuers, a group of orphans and a press ombudsman. The choice to publish so many demand images can be linked to the fact that the people involved were still waiting for official answers and more active public involvement.

The selected offer images addressed the viewers indirectly in the sense that they contained no actor looking directly at the viewer. All images offered information not only about the fact that some people had been rescued, but also that the victims had not been forgotten. Images that were narratively structured represented survivors during or immediately after the rescue operation, people in front of the MS Estonia memorial wall (2004), in front of a big cross at Ersta Church (2009) and the King of Sweden laying flowers on the memorial wall (published twice in 2014). In all of these images, 'the viewer's role is that of an invisible onlooker' (Kress \& van Leeuwen, 2006: 119), witnessing the ongoing process of dealing with the disaster and its consequences. Although offer images generally require less engagement from the viewers, they were supposed to have a strong impact because of their narrative structures. The other, conceptually 
structured, offer images appeared only in 2014. They had an impact on the relationship with the viewer by portraying victims, survivors and family members only in close-up or medium shots to bring the represented social actors closer to the viewer.

\section{Discussion}

\section{Visual representation of the MS Estonia disaster over time}

Our findings demonstrate that a series of changes occurred in the visual representation of the MS Estonia disaster from 2004 to 2014 in the Scandinavian press. Although the focus of the conceptual images remained on the loss, this shifted from the scarce visualisation of impersonal loss in 2004 and 2009 (an empty sea) to the detailed visualisation of personal loss in 2014. The publication of the ROV photo of the shipwreck in 2004, 2009 and 2014 marked a symbolic connection between the three commemorative milestones, suggesting the permanence of the loss. The empty sea that appeared twice in 2004 was replaced in 2014 by diverse images depicting floating objects that brought the human factor into focus in two ways: by visualising the cruise ferry still floating before the shipwreck and the various lifesaving vessels used during the rescue operation. The loss also became more personalised in 2014 through images of the disaster's aftermath: cabin keys and coffins.

The visualisation of the personal loss in the conceptual images of 2014 included not only such objects, but also actors who have been directly or indirectly involved in the disaster. As already shown, the main actors visualised in 2014 were those directly involved in the disaster either as victims or as survivors. Additionally, the visual inclusion of those who had been involved indirectly added more concrete information about the identity of all those who have been affected by the crisis.

If the narrative images published in 2004 and 2009 were mainly images of bereaved family members, those appearing in 2014 included more categories of actors: victims, survivors in various contexts and even the King of Sweden. This change brought the disaster closer to the viewers - as if the disaster were happening again in front of their eyes. The graphic visualisation of the sinking, together with the images of the rescue and hoisting operations, also contributed to a re-actualisation of the still unanswered questions related to the disaster. The recurrent publication of the wreck-hoisting image in 2014 also implicitly reiterated the questions about the possible cause of the disaster and became a visual symptom of the 'crisis after the crisis', when the identity of the original crisis shifts over time (Rosenthal et al., 1989).

When analysing how the ideational metafunction was accomplished by the $2014 \mathrm{im}$ ages, it appeared that the strategic choice of images had two significant consequences. First, by visualising the disaster as a process, the images clarified its impact, bringing it closer to the viewers. Second, by visualising a wider range of actors involved in more diverse types of actions than in the previous years, the images gave these actors a voice in the rhetorical arena, and had them intervene in the 'crisis after the crisis'.

As far as the interpersonal metafunction is concerned, it was evident that the positioning of the viewer had also changed as time passed, because the sheer number of images increased for the anniversary reporting in 2014. That demand and offer images were equally present in 2014 indicated that viewers were both offered more detailed information and were also implicitly asked to enter the rhetorical arena and get involved. 
Taking everything into account, it became evident that the visual resources selected by the Scandinavian press in 2014 were meant to revive the tragedy and the still unsolved issues in a much more vivid way than in 2004 and 2009. By visually re-opening the rhetorical arena, the Scandinavian press provided not only a more nuanced reminder of the disaster, but also contributed to the resurgence of the "crisis after the crisis".

Table 3. Overview of findings

\begin{tabular}{|c|c|c|c|c|}
\hline Choices Years & $\begin{array}{l}2004 \\
7 \text { images }\end{array}$ & $\begin{array}{l}2009 \\
2 \text { images }\end{array}$ & $\begin{array}{l}2014 \\
84 \text { images }\end{array}$ & $\begin{array}{l}\text { Consequences of } \\
\text { changes across } \\
\text { years }\end{array}$ \\
\hline \multirow{2}{*}{$\begin{array}{l}\text { Ideational } \\
\text { choices: } \\
\text { Conceptual } \\
\text { and narrative } \\
\text { structures }\end{array}$} & $\begin{array}{l}\text { Visualisation of imper- } \\
\text { sonal loss: symbolic } \\
\text { absence (the empty } \\
\text { sea) and concrete } \\
\text { consequences (the } \\
\text { wreck) }\end{array}$ & $\begin{array}{l}\text { Visualisation of } \\
\text { impersonal loss: } \\
\text { concrete conse- } \\
\text { quences (the wreck) }\end{array}$ & $\begin{array}{l}\text { Visualisation of the } \\
\text { MS Estonia before the } \\
\text { disaster } \\
\text { Visualisation of } \\
\text { impersonal and per- } \\
\text { sonal loss: symbolic } \\
\text { absence (similarity } \\
\text { \& replacement) and } \\
\text { concrete consequen- } \\
\text { ces (wreck, coffins, } \\
\text { survivors, those left } \\
\text { behind) }\end{array}$ & $\begin{array}{l}\text { Richer informa- } \\
\text { tion about the } \\
\text { disaster and its } \\
\text { consequences } \\
\text { From impersonal } \\
\text { to personal loss: } \\
\text { the human factor } \\
\text { more in focus }\end{array}$ \\
\hline & $\begin{array}{l}\text { Visualisation of the } \\
\text { sinking process (com- } \\
\text { posite graphic image) } \\
\text { Visualisation of the } \\
\text { grieving process }\end{array}$ & $\begin{array}{l}\text { Visualisation of the } \\
\text { grieving process }\end{array}$ & $\begin{array}{l}\text { Visualisation of the } \\
\text { sinking (maps), rescue, } \\
\text { hoisting and grieving } \\
\text { processes }\end{array}$ & $\begin{array}{l}\text { More actors enter } \\
\text { the rhetorical } \\
\text { arena } \\
\text { The disaster } \\
\text { as a process is } \\
\text { brought closer to } \\
\text { viewers }\end{array}$ \\
\hline \multirow{2}{*}{$\begin{array}{l}\text { Interpersonal } \\
\text { choices: } \\
\text { Demand and } \\
\text { offer images }\end{array}$} & $\begin{array}{l}\text { Only one demand } \\
\text { image }\end{array}$ & No demand image & 17 demand images & $\begin{array}{l}\text { Viewers are } \\
\text { implicitly asked to } \\
\text { enter the rhetori- } \\
\text { cal arena and get } \\
\text { involved }\end{array}$ \\
\hline & Only one offer image & $\begin{array}{l}\text { Only one offer } \\
\text { image }\end{array}$ & 25 offer images & $\begin{array}{l}\text { The viewers are } \\
\text { offered more } \\
\text { detailed informa- } \\
\text { tion }\end{array}$ \\
\hline $\begin{array}{l}\text { Textual choices: } \\
\text { Salience and } \\
\text { framing }\end{array}$ & Neutral layout & Neutral layout & $\begin{array}{l}\text { More complex layout } \\
\text { with eye-catching } \\
\text { features }\end{array}$ & $\begin{array}{l}\text { Enhancement of } \\
\text { visual information } \\
\text { Enhancement of } \\
\text { viewer involve- } \\
\text { ment }\end{array}$ \\
\hline
\end{tabular}

\section{News media: Influential voices in the rhetorical arena}

According to rhetorical arena theory (RAT), what the news media write about a crisis - before, during and after it occurs - must also be considered crisis communication. Indeed, the news media represent some of the most influential voices during a crisis situation. Our longitudinal study of the images accompanying Scandinavian press reports about the MS Estonia disaster, and how the images changed over time, is one of the first studies of visual crisis communication involving a large corpus of empirical data. Out of the three roles listed up by Horsley (2016) in the introduction, investigators, critics and historians, the 15 newspapers from Sweden, Norway and Denmark first and foremost 
served as historians. This is no surprise, given that our longitudinal study focused on how the Scandinavian press transformed the disaster into a social icon over a period of 20 years. If the study only focused on the disaster which took place on 28 September 1994, we would have expected that the press would have served as investigators or critics and the disaster would have been considered a focusing event (Birkland, 1997). Focusing events are likely to induce media coverage when the number of people affected is high, the consequences are visible and tangible and the event is rare and dramatic (Birkland, 1997).

According to RAT and the type of crisis journalism that can be developed within the arena framework (Frandsen \& Johansen, 2017a), we would have expected to see a little more media intervention - that is, reporters chasing the organisation perceived to be guilty in the MS Estonia disaster. However, in this case, the media coverage dominated. We seldom saw persuasive attacks performed by investigative journalists, and the news media are not rich in crisis news frames (see An \& Gower, 2009).

\section{Ritualisation of commemoration and choice of images}

Some moments are more important than others. Ritualised years of commemoration - such as twentieth anniversaries - seem to be extremely important at least in terms of the number of images presented. The Scandinavian press choose visuals to inform and emotionally involve viewers in the drama by representing what happened during and after the disaster. The anniversary visuals also included post-crisis pictures of survivors and families as well as pictures of memorials and commemorative events. The further away from the original event, the more important it became to cover the human stories and involve viewers through more personalised stories about victims and survivors. The choice of images thus seems to follow a somewhat 'classical' pattern describing a dramatic event over time. There were also images that obtained a more symbolic value through repetition (e.g. the hoisting of the bow door), and the repetitive use of specific images provided symbolic or iconic status to a specific framing of the event. For example, the hoisting of the bow door became a symbol pointing to the cause of the disaster. More importantly, the bow door was the only component of the cruise ferry which was raised - the bodies beneath the waves still have not been recovered. This unbearable situation for their relatives and the survivors caused a second crisis, so we are dealing with 'a crisis after a crisis' (theoretical underpinnings for these concepts and discussion of crisis identity shifts are beyond the scope of this article; cf. Frandsen \& Johansen, 2017a).

What did the images not include? As already mentioned, there were no images representing the owner of the cruise ferry, Estline, except for the long shot photos in which the name of the maritime company was visible on the port side of the ferry. This may be explained by the complexity of the organisational ownership of this crisis, and the choice between verbal and visual resources to tell different parts of the story. The verbal text discussed the unsettled issues such as what caused the ship to sink, the involved actors and the parties responsible.

The MS Estonia remains a disaster with many unsettled issues. Not only was the cause never fully accepted by all parties - and there are still rumours about sabotage but the relatives have not been satisfied either, because they have not been able to bury 
their loved ones. The disaster still puzzles numerous people, and this may explain the attention that it still attracts even 20 years after the event.

Throughout history, many shipping disasters have not only been focusing events, but have also become social icons, from the RMS Titanic (1912) to the Scandinavian Star (1990). Some crises transform into 'social icons, around which broader meaning is constructed, maintained, symbolized and conveyed' (Seeger et al., 2003: 6; cf. Frandsen \& Johansen, 2017b). The MS Estonia disaster constitutes a focusing event, as the media coverage was intense not only in 1994 but up to 20 years later - has it also transformed into a social icon? Has it brought people together and provided them with elements of a collective identity and memory? The commemoration of the anniversaries points in this direction, although the issues connected to the causes and consequences are still not clear (see Frandsen \& Johansen (2017b) for an elaboration).

\section{Conclusion and future research}

This study explored the use of images by the Scandinavian press when reporting on and/ or commemorating the anniversaries of the MS Estonia disaster 5, 10 and 20 years after the event and contributes to the emerging field of visual crisis communication. Through the choice of images to report what happened on 28 September 1994, the Scandinavian press visualised the devastating material (the wreck) and its human consequences (personal loss) to the viewer. The images changed over time and increasingly engaged viewers through personalised human stories and the incorporation of more actors. Certain images obtained symbolic value over the years; the hoisting of the bow door, for example, represented the crisis after the crisis and related unsettled issues. Human interest and emotion (Fahmy et al., 2007) also remained a strong criteria for the choice of press photos when reporting upon the commemorating anniversaries of the event (for visual agenda setting, see de Smaele et al., 2017).

This study makes important contributions to the field of visual crisis communication, and provides new insight into RAT, showing how the news media made use of visual resources (images) to intervene in the representation and interpretation of a specific crisis at both the moment of crisis and over time. Methodologically, instead of applying traditional content analysis in which the collected texts are dissolved into lexical items or themes, we used a social semiotic approach to visual analysis based on the idea of verbal and visual elements as an important semiotic resource for representing the world that interact with each other and combine linguistic units into texts. This study opens the possibility for other researchers involved in similar longitudinal studies to apply the same approach and analytical tools when studying images of various types of crises.

Our study is of practical relevance to organisations and communication professionals. Gaining expertise in understanding the role and function of crisis visuals enables communication professionals to anticipate the possible visual development of the news media coverage and address the news media intervention strategically. A crisis 'speaks' different languages, using both words and images. Organisations and/or stakeholders who do not understand how to manage and participate in the visual mode of meaning production face a difficult future, as visuals have come to play an increasingly important role in the age of digital media. 


\section{Note}

The authors have contributed equally to this article.

\section{References}

An, S. K. \& Gower, K. K. (2009). How do the news media frame crisis? A content analysis of crisis news coverage. Public Relations Review, 35(2): 107-112.

Bednarek, M. \& Caple, H. (2017). The discourse of news values: How news organizations create newsworthiness. New York, NY: Oxford University Press.

Birkland, T. A. (1997). After disaster: Agenda setting, public policy, and focusing events. Washington, DC: Georgetown University Press.

Boin, A., 't Hart, P., Stern, E. \& Sundelius, B. (2005). The politics of crisis management - Public leadership under pressure. Oxford: Oxford University Press. 2nd Ed. 2016.

Boltanski, L. (2004). Distant suffering: Morality, media and politics. Cambridge: Cambridge University Press.

Bos, C. K., Ullberg, S. \& 't Hart, P. (2005). The long shadow of disaster: Memory and politics in Holland and Sweden. International Journal of Mass Emergencies and Disasters, 23(1): 5-26.

Bryman, A. (2012). Social research methods. Oxford: Oxford University Press.

Claeys, A.-S. \& Cauberghe, V. (2014). Keeping control: The importance of nonverbal expressions of power by organizational spokespersons in times of crisis. Journal of Communication, 64(6): 1160-1180.

Collister, S. \& Roberts-Bowman, S. (eds.) (2018). Visual public relations: Strategic communication beyond text. London: Routledge

Coombs, W. T. \& Holladay, S. J. (2011). An exploration of the effects of victim visuals on perceptions and reactions to crisis events. Public Relations Review, 37(2): 115-120.

Courtright, J. L. \& Slaughter, G. Z. (2007). Remembering disaster: Since the media do, so must public relations. Public Relations Review, 33: 313-318.

Dahmen, N. S. \& Miller, A. (2012). Redefining iconicity: A five-year study of visual themes of Hurricane Katrina. Visual Communication Quarterly, 19(1): 4-19.

de Smaele, H. Geenen, E. \& De Cock, R. (2017). Visual gatekeeping - Selection of news photographs at a Flemish newspaper. A qualitative inquiry into the photo news desk. Nordicom Review, 38 (Special Issue 2): 57-70.

Fahmy, S., Cho, S., Wanta, W. \& Song, Y. (2006). Visual agenda setting after 9/11: Individual emotion, recall and concern about terrorism. Visual Communication Quarterly, 13: 4-15.

Fahmy, S., Kelly, J. D. \& Kim, Y. S. (2007). What Katrina revealed: A visual analysis of the hurricane coverage by news wires and U.S. newspapers. Journalism and Mass Communication Quarterly, 84(3): 546-561.

Frandsen, F. \& Johansen, W. (2010). Crisis communication, complexity and the cartoon affair: A case study. In W. T. Coombs \& S. J. Holladay (eds.), The handbook of crisis communication (pp. 425-448). Boston, MA: Wiley-Blackwell.

Frandsen, F. \& Johansen, W. (2015). Organizations, stakeholders and intermediaries. Toward a general theory. International Journal of Strategic Communication, 9(4): 253-271.

Frandsen, F. \& Johansen, W. (2017a). Organizational crisis communication: A multivocal approach. London: Sage.

Frandsen, F. \& Johansen, W. (2017b). The MS Estonia disaster: The construction of a social icon in the news media. Paper presented at the International Crisis and Risk Communication Conference, 2017 March 13-15, University of Central Florida, Orlando, FL.

Horsley, S. J. (2016). Media framing of disasters: Implications for disaster response communication. In A. Schwarz, M. W. Seeger \& C. Auer (eds.), The handbook of international crisis communication research (pp. 155-164). Chichester: Wiley Blackwell

Joye, S. (2014). Media and disasters: Demarcating an emerging and interdisciplinary area of research. Sociology Compass, 8(8): 993-1003.

Kedra, J. (2016). Enhancing visual literacy through interpretation of photo-genres: Toward a genre typology of journalistic photographs. Journal of Media Practice, 17(1): 28-47.

Kress, G. \& van Leeuwen, T. (2006). Reading images: The grammar of visual design. London: Routledge. Lippmann, W. (1922). Public opinion. New York: Harcourt, Brace \& Co.

Liu, B. F., Wood, M. M., Egnoto, M., Bean, H., Sutton, J., Mileti, D. \& Madden, S. (2017). Is a picture worth a thousand words? The effects of maps and warning messages on how publics respond to disaster information. Public Relations Review, 43(3): 493-506.

Lundby, K. (2009). Introduction: 'Mediatization' as key. In K. Lundby (ed.), Mediatization: Concept, changes, consequences (pp. 1-18). New York, NY: Peter Lang. 
Machin, D. \& Polzer, L. (2015). Visual journalism. London: Palgrave.

Maier, C. D. (2020, forthcoming). Visual crisis communication. In F. Frandsen \& W. Johansen (eds.), Crisis communication. Handbooks of Communication Science Vol. 23. Berlin: Mouton de Gruyter.

Miller, A. \& LaPoe, V. (2016). Visual agenda-setting, emotion, and the BP oil disaster. Visual Communication Quarterly, 23(1): 53-63.

Pallas, J. \& Fredereriksson, M. (2013). Corporate media work and micro-dynamics of mediatization. European Journal of Communication, 28(4): 420-435.

Patrona, M. (ed.) (2018). Crisis and the media: Narratives of crisis across cultural settings and media genres. Amsterdam: John Benjamins.

Rosenthal, U. Charles, M. T. \& 't Hart, P. (1989). Coping with crises: The management of disaster, riots and terrorism. Springfield, IL: Charles C. Thomas Publisher.

Seeger, M. W., Sellnow, T. L. \& Ulmer, R. R. (2003). Communication and organizational crisis. Westport, CT: Praeger.

Copyright: (C) 2019 The Author(s) and Nordicom. This is an open-access article distributed under the terms of the Creative Commons Attribution 4.0 International License (CC BY-NC-ND 4.0). 